\title{
PENERAPAN TEKNOLOGI BLOCKCHAIN DALAM LINGKUNGAN PENDIDIKAN
}

\author{
Ade Chandra Nugraha \\ KBK Sistem Informasi dan Database - Jurusan Teknik Komputer dan Informatika \\ Politeknik Negeri Bandung, Bandung 40012 \\ Email : chandra@jtk.polban.ac.id
}

\begin{abstract}
Abstraksi
Sebagai inovasi yang relatif baru dalam ilmu komputer, Blockchain adalah teknologi global, lintas industri, dan disruptif yang diperkirakan akan memicu pertumbuhan ekonomi global. Blockchain adalah sebuah sistem penyimpanan data digital yang terdiri dari banyak server (multiserver). Pada teknologi Blockchain, data yang dibuat oleh satu server dapat direplikasi dan diverifikasi oleh server yang lain. Pemanfaatan Blockchain tak sebatas pada mata uang kripto. Sebab, teknologi yang berfungsi merekam data dan transaksi mini bisa digunakan untuk banyak sektor seperti pencatatan proses transaksi, dokumentasi, bahkan pemungutan suara. Dalam tulisan ini, penulis akan menyajikan usecase yang relevan dalam penggunaan teknologi Blockchain di lingkungan Pendidikan, khususnya pengolahan data di perguruan tinggi.
\end{abstract}

Kata Kunci :

Blockchain, penyimpanan data digital, pengolahan data di perguruan tinggi

\begin{abstract}
Blockchain is a new innovation in computer science. This technology involved cross-industry and disruptive technology that is expected to trigger global economic growth. Blockchain is a digital data storage system that consists of many servers (multiserver). In Blockchain technology, data created by one server and can be replicated and verified by another server. Utilization of Blockchain is not limited to crypto currencies. Therefore, technology that functions to record data and mini transactions can be used for many sectors such as recording the transaction process, documentation, and even voting.

In this paper, the author will present relevant usecase in the use of Blockchain technology in the Education environment, specifically data processing in Vocational Higher Education.
\end{abstract}

\section{Keywords:}

Blockchain, a digital data storage, Data Processing in Vocational Higher Education

\section{Pendahuluan}

Blockchain adalah teknologi informasi terkini, dan saat ini sudah mulai banyak diterapkan dalam kebutuhan sehari-hari di berbagai bidang terapan. Teknologi ini dikembangkan dalam rangka mendukung era disruption informasi yang memberi alternatif solusi dari arsitektur teknologi yang terpusat. Teknologi Blockchain direalisasikan dengan konsep desentralisasi informasi dalam pengolahan datanya. Data dalam Blockchain disimpan secara permanen dalam record data yang akan dikomunikasikan secara peer-to peer dalam jaringan internal dan berkolaborasi secara aktif. Hal ini sangat berbeda dengan konsep internet-based yang berkembang di teknologi informasi sebelumnya. Teknologi Blockchain digembar-gemborkan sebagai teknologi yang akan menggantikan arsitektur informasi terpusat yang saat ini dominan dikembangkan, yaitu melalui implementasi teknologi internet-based.

Peluang dan tantangan pergeseran teknologi dari internet-based ke model peer-to-peer mulai banyak diakomodasi oleh praktisi di industri maupun bisnis. Usecase awal dari implementasi teknologi Blockchain adalah sebagai mata uang kripto yang biasa digunakan untuk transaksi bisnis, sehingga beberapa konsep penjagaan keamanan dari transaksi tersebut sangat dipentingkan. Di sisi lain, pendidikan tinggi sebagai institusi non bisnis 
tertantang juga untuk mencoba mengadaptasi konsep dan implementasi teknologi Blockchain ke dalam bisnis utama pendidikan tinggi yaitu proses pembelajaran dan pendidikan. Dalam makalah ini akan diuraikan apa saja kekuatan teknologi Blockchain dalam menunjang kebutuhan proses di pendidikan tinggi.

Dalam dunia Pendidikan, penerapan teknologi Blockchain masih belum banyak diterapkan, selain karena teknologi ini sering dicontohkan untuk penanganan informasi keuangan, kontrak pekerjaan yang melibatkan sekumpulan transaksi keuangan dan ecommerce juga dikarenakan kekurang pedulian para pemangku kepentingan di dunia pendidikan akan manfaat social dan potensi dari teknologi Blockchain.

\section{Teknologi Blockchain}

"Blockchain" dengan cepat menjadi bagian dari teknologi vernakular, namun masih sangat disalahpahami. Definisi Blockchain [7] adalah buku besar yang didistribusikan. Dalam pendistribusian nya teknologi ini menyediakan cara agar informasi dapat direkam dan dibagikan oleh suatu komunitas. Di komunitas ini, setiap anggota menyimpan salinan informasi mereka, dan setiap terjadi transaksi maka semua anggota akan memvalidasi pembaharuan tersebut secara kolektif. Informasi dalam Blockchain dapat mewakili transaksi, kontrak, aset, identitas, atau apa pun yang dapat dijelaskan dalam bentuk digital. Entri bersifat permanen, transparan, dan dapat dicari, yang memungkinkan anggota komunitas untuk melihat riwayat transaksi secara keseluruhan. Setiap pembaruan adalah "blok" baru yang ditambahkan ke akhir "rantai"/chain. Protokol mengatur bagaimana aktualisasi atau entri data dilaksanakan, divalidasi, direkam, dan didistribusikan. Dengan Blockchain, kriptologi menggantikan peran perantara pihak ketiga dengan menjalankan algoritma kompleks untuk mengesahkan integritas seluruh block.

Percobaan dengan topik Blockchain diawali sejak awal 1990-an, tetapi baru pada tahun 2008 dikeluarkan sebuah whitepaper dari kelompok individu yang beroperasi di bawah nama samaran Satoshi Nakamoto. Blockchain pertama yang terkenal adalah Bitcoin Blockchain, yang juga merupakan nama cryptocurrency yang pertama kali digunakan secara luas dan terdesentralisasi. "Bitcoin" mengacu pada protokol jaringan yang mendasari cryptocurrency. Selain bitcoin, teknologi Blockchain lain yang sudah dipakai di masyarakat adalah Ethereum.

Blockchain adalah record (basis data) yang terus berkembang, disebut block, yang terhubung dan diamankan menggunakan teknik kriptografi. Setiap blok memuat hash kriptografis dari blok sebelumnya, timestamp, dan data transaksi. Setiap block pada sistem ini saling terkait dan jika ada upaya untuk mengubah data pada satu block, maka harus mengubah data pada block yang lain. Masing-masing block yang dilindungi oleh kriptografi ini saling terhubung dan membuat suatu jaringan. Semua komputer dalam jaringan secara kontinyu dan matematis memverifikasi salinan Blockchain dengan semua salinan lain di jaringan.

Aplikasi Blockchain yang dikenal luas saat ini adalah sebuah ledger/buku besar transaksi yang menerapkan cryptocurrency, seperti Bitcoin dan Ether. Dalam sebuah ledger publik, Blockchain memberikan catatan asal dan pengalihan kepemilikan suatu aset. Struktur transaksional protokol Blockchain memfasilitasi tidak hanya transfer mata uang digital, tetapi juga aset digital lainnya. Aset dapat berwujud, seperti rumah, mobil, uang tunai, tanah, atau tidak berwujud seperti kekayaan intelektual, seperti paten, hak cipta, atau merek. Secara virtual, segala sesuatu yang bernilai dapat dilacak dan diperdagangkan di jaringan Blockchain, mengurangi risiko dan memangkas biaya untuk semua yang terlibat [4]. Properti kunci lainnya yang terkait dengan Blockchain adalah keamanan, imutabilitas dan programabilitas, yang menjadi karakter protokol konsensus yang dijalankan.

\section{Sosio Teknologi dalam Blockchain}

Dalam pengembangan dan penerapan Blockchain, kecenderungan pengguna lebih difokuskan pada penerapan teknologi tsb di permasalahan yang berkaitan dengan digital disruption, ekonomi digital, industri pengetahuan dan sistem inovasi. Hal ini memungkinkan para pengembang untuk memahami konteks gangguan digital. Namun, biasanya bukan hanya teknologi digital yang penting, namun juga pentrigger sosial-ekonomi yang menciptakan permintaan untuk teknologi (atau perubahan dalam menanggapi teknologi tsb) juga perlu diperhatikan. Christensen dalam [2] menyatakan bahwa dalam merancang sebuah bisnis digital yang harus pertama disiapkan adalah bagaimana membuat orang memahami akan kebutuhannya, barulah mengidentifikasi teknologi digital yang dapat mensolusikannya. Mengadaptasi argumen Christensen di atas, maka Gupta [4], Hanson et. al [6], dan Piscini et al. [7], mengusulkan seperangkat prinsip dasar yang mendukung proposisi nilai sosial teknologi dari Blockchain untuk menerapkan teknologi Blockchain di sektor pendidikan.

Sosio teknologi yang dapat diacu dalam penerapan teknologi Blockchain dikelompokan menjadi 6 fitur, yaitu :

a. Self-Sovereignty, yaitu adanya kebebasan kepada kemampuan individu dalam mengidentifikasi dan menshare data maupun informasi yang dimiliki. Sehingga pengguna Blockchain diberi otoritas 
b. Trust, Teknologi Blockchain disiapkan untuk saling bertransaksi dalam lingkungan yang aman karena adanya transaksi peer-to peer antar konsensus yang diciptakan dengan tingkat keamanan yang tinggi melalui implementasi cryptocurrency yang mengutamakan otentikasi dan otorisasi;

c. Transparency and Provenance, sehingga setiap transaksi yang terjadi dalam teknologi Blockchain relative transparan dan berasal dari pihak yang terverifikasi;

d. Immutability, terkait dengan keamanan, ketahanan dan kekekalan dokumen/asset yang ditransaksikan karena data/informasi yang sudah dientrykan tidak dapat dihapus maupun diubah sepihak tanpa memperhatikan pihak lain yang terlibat dalam konsensus yang dibentuk;

e. Disintermediation, dengan teknologi Blockchain, algoritma konsensus peer-to-peer secara transparan mencatat dan memverifikasi transaksi tanpa pihak ketiga, sehingga berpotensi mengurangi atau bahkan menghilangkan biaya, keterlambatan, dan kompleksitas umum yang mungkin terjadi;

f. Collaboration, semua transaksi peer-to peer dilakukan dalam jaringan internal yang melibatkan konsensus tertentu dimana antar pihak yang terlibat harus memperhatikan dan beritikad sama untuk merealisasikan 5 keutamaan dari teknologi Blockchain di atas.

\section{Metode Penelitian}

Pembahasan dilakukan dengan menguraikan kajian pustaka terkait karakteristik dari teknologi Blockchain. Untuk menerapkan teknologi Blockchain dalam cakupan bidang non komersial (pendidikan tinggi) maka diperlukan adanya dimensi / sudut pandang lain agar teknologi Blockchain dapat memaksimalkan ruang lingkup di bidang tersebut. Dan salah satu sudut pandang yang dapat digunakan adalah dengan memperhatikan dampak sosio teknologi dari Blockchain. Dengan memperhatikan dampak dari sosio teknologi nya maka dilakukan survey dan pengumpulan data yang relevan dalam lingkungan implementasi di program studi tempat penyusun bekerja. Hasil dari pengumpulan fakta ini disimpulkan agar penerapan teknologi Blockchain dapat mengoptimalkan bisnis proses di bidang pendidikan tinggi.

\section{Pembahasan}

Dalam dunia Pendidikan, penerapan teknologi Blockchain masih belum banyak diterapkan, selain karena teknologi ini masih sangat baru, juga penarik awal dari bidang terapan blockchain ini yang mengemuka adalah yang terkait dalam pemberian solusi terhadap permasalahan ekonomi dan bisnis. Dalam makalah ini dilakukan pembahasan terkait penerapan teknologi blockchain yang tidak mengarah pada cryptocurrency yang sudah banyak diulas dalam tulisan lain. Penerapan blockchain dalam dunia pendidikan dalam tulisan ini mengacu pada indikator sosio teknologi untuk menerapkan teknologi Blockchain, seperti yang telah dibahas dalam sub bab sosio teknologi di atas. Indikator proporsi sosial teknologi dalam penerapan Blockchain dapat diuraikan seperti dalam tabel 1 berikut :

Tabel 1 : Indikator proporsi sosial teknologi dalam penerapan Blockchain

\begin{tabular}{|c|l|c|c|c|c|}
\hline & $\begin{array}{c}\text { Karakteristik Sosial } \\
\text { Teknologi }\end{array}$ & $\begin{array}{c}\text { Pemerintah/ Penentu } \\
\text { kebijakan }\end{array}$ & $\begin{array}{c}\text { Industri/stakeholders } \\
\text { / pengguna lulusan }\end{array}$ & $\begin{array}{c}\text { Institusi } \\
\text { pendidikan }\end{array}$ & Pembelajar \\
\hline 1 & $\begin{array}{l}\text { Self-Sovereignty and } \\
\text { Identity }\end{array}$ & Tinggi & Tidak pasti & Tenengah & Tinggi \\
\hline 2 & Trust & Tinggi & Tinggi & Tinggi & Tinggi \\
\hline 3 & $\begin{array}{l}\text { Transparency and } \\
\text { Provenanc }\end{array}$ & Tidak pasti & Tinggi & Menengah & Menengah \\
\hline 4 & Immutability & Tinggi & Menengah & Tinggi & Tidak pasti \\
\hline 5 & Disintermediation & Tinggi & Rendah & & \\
\hline
\end{tabular}

Dengan memperhatikan Tabel 1 di atas, maka hasil identifikasi dan wawancara yang dilakukan di tingkat jurusan teknik komputer dan informatika (JTK) Politeknik negeri Bandung (POLBAN) dapat diuraikan beberapa usecase penerapan Blockchain sebagai berikut :

\section{Sebagai Identitas Digital}

Dengan diterapkan nya Blockchain dalam mengelola identitas digital di dunia pendidikan diharapkan dapat meningkatkan efektifitas proses maupun pendanaan dalam rutinitas proses di lingkungan pendidikan. Selain itu, blockchain dapat memudahkan proses pelacakan, mampu mengelola identitas digital dengan lebih aman dan 
efisien. Bahkan, dapat meminimalisir terjadinya penipuan. Identitias digital dengan bantuan Blockchain cukup berbeda, otentikasi sistemnya berdasarkan verifikasi menggunakan tanda tangan digital secara kriptografi. Transaksi juga ditandatangani hanya dengan private key yang benar-benar dimiliki oleh pemiliknya saja. Maka selain dari pemilik identitas ini, sudah bisa dipastikan tidak akan dapat mengakses karena key yang digunakan dianggap tidak valid.

Penggunaan teknologi Blockchain sebagai identitas digital ini, dapat diterapkan pada beberapa aktivitas berikut: Identitas Digital untuk berbagai kebutuhan identifikasi, Portofolio sivitas akademika, Absensi kehadiran siswa dan staf JTK POLBAN.

\section{Sebagai Storage yang terdistribusi di Cloud.}

Diyakini, dalam jangka waktu 3-5 tahun mendatang, ruang penyimpanan data cloud yang berbasis blockchain juga akan banyak digunakan. Jika selama ini cloud storage umumnya banyak menggunakan sistem yang terpusat, maka lebih lanjut, bisa berubah menjadi sistem yang terdesentralisasi. Sehingga kontrol data tersebut tidak bergantung lagi pada penyedia layanan tertentu.

Blockchain dapat digunakan sebagai media alternatif untuk penyimpanan dokumen digital. Dokumen digital dapat diidentikan sebagai sehelai kertas yang sering dikeluarkan dalam format eksklusif oleh vendor kepada pelanggan, lembaga tanpa perangkat lunak yang tepat mungkin tidak dapat membaca atau memverifikasinya. Akhirnya, seperti dokumen kertas, dokumen digital juga dapat dipalsukan oleh pengguna canggih dengan cara yang sulit dideteksi, dan hal ini tentunya membutuhkan pengembangan fitur dalam penerapan teknologi Blockchain sebagai media penyimpanan yang terdistribusi di cloud.

Dokumen digital yang dapat disimpan dapat berupa buku besar hasil proses akademik di lingkup jurusan maupun program studi, buku besar hasil penelitian maupun kajian dalam tugas akhir mahasiswa JTK. Selain digunakan untuk menyimpan buku besar akademik, media storage di cloud juga dapat digunakan untuk menyimpan profil dan portofolio mahasiswa beserta prestasi akademik yang sudah diperolehnya.

Dokumen digital, berupa artifak maupun dokumen teknis yang terkait dengan proses penelitian di JTK akan dapat dikembangkan untuk dijadikan database kekayaan intelektual dari sivitas akademika JTK POLBAN. Dengan terdokumentasikan dalam bentuk digital, maka kiprah sivitas akademika JTK POLBAN di dunia penelitian dan kerjasama penerapannya akan lebih tersosialisasikan dan tentunya mendukung pada penerbitan paten maupun HKI yang dapat dikomersialisasikan dengan menerapkan cryptocurrency yang relatif sesuai dengan lingkungan dan roadmap penelitian di JTK POLBAN.

\section{Sebagai Pengawas yang terdesentralisasi.}

Dalam era digital, semua aktivitas membutuhkan adanya sistem yang terdesentralisasi, sehingga role pengawas pun bisa diaplikasikan melalui sistem yang terdesentralisasi. Salah satu hal yang membuat teknologi Blockchain dapat dipergunakan untuk pengawasan artifak digital adalah karena Blockchain mempunyai fungsi timestamp. Dengan adanya fungsi timestamp yang dibubuhkan pada sebuah data, maka dapat digunakan untuk menegaskan keberadaan suatu data. Tentu saja, berdasarkan waktu yang telah disebutkan dan melekat pada data tersebut. Seluruh jaringan, kemudian memberikan validasi data tersebut dan meletakkan hash dibagian headernya.

Peran pengawas dalam pendikan adalah adanya peran memverifikasi dan menerbitkan dokumen kredential, seperti sertifikat atau transkrip nilai secara digital dengan keutamaan proses validasi dan verifikasi yang akan mengurangi terjadinya pemalsuan maupun pengubahan isi informasi. Dalam penerapan teknologi Blockchain cakupan ini lebih dikenal dengan istilah smart contract. Smart contract adalah program komputer kecil yang secara efektif disimpan di Blockchain. Program kecil ini akan melakukan transaksi dalam kondisi tertentu. Dengan demikian, Smart contract biasanya merupakan deklarasi seperti "transfer X ke Y jika Z terjadi". Tidak seperti kontrak reguler, di mana setelah mencapai kesepakatan para pihak harus mengeksekusi isi kontrak, maka kontrak yang cerdas adalah self executing - yaitu, setelah instruksi ditulis ke Blockchain, transaksi akan berlangsung secara otomatis ketika kondisi yang sesuai terdeteksi, tanpa adanya intervensi dari para pihak yang bertransaksi atau pihak ketiga lainnya.

Bentuk record lainnya adalah sertifikat dan tandatangan digital. Dalam bentuknya yang paling esensial, sertifikat adalah masalah pernyataan dari satu pihak ke pihak lain bahwa serangkaian fakta tertentu benar. Tanda tangan adalah bukti bahwa pernyataan itu dikeluarkan dari dan ke pihak-pihak terkait. Blockchain dapat digunakan untuk menyimpan hash kriptografi ("sidik jari digital") dari sertifikat, atau untuk menyimpan klaim yang terjadi. Dengan demikian, Blockchain dapat berfungsi sebagai pengelola sertifikat publik. Ketika teknologi Blockchain digunakan dalam pengelolaan sertifikat/dokumen kredensial lainnya, ada peluang untuk tidak hanya memverifikasi dokumen kredensial tanpa perantara, tetapi untuk memperkaya dan menambah nilai pada ekosistem sertifikasi 
digital yang sudah ada untuk menyediakan digital sertifikasi kepada siswa di beberapa lembaga akademik. Oleh karena itu, tujuan pengawas sertifikat pada Blockchain adalah untuk mengubah sertifikat digital yang biasanya diterima siswa secara pribadi menjadi informasi yang dapat diverifikasi secara otomatis yang dapat dikonsultasikan oleh pihak ketiga melalui sistem bukti yang tidak dapat diubah pada Blockchain.

\section{Kesimpulan}

Pemanfaatan teknologi Blockchain dalam dunia pendidikan bukan hal yang berbeda dengan penerapan di bidang komersial atau transaksi yang melibatkan dana. Banyak artifak dan dokumen di bidang pendidikan yang dapat dijadikan aset yang berguna sehingga dapat dijadikan modal untuk bertransaksi dalam konteks yang aman dan memenuhi kebutuhan dari semua pihak yang terlibat.

Dalam penelitian yang mendasari penulisan artikel ini, diacu peran sosio teknologi dalam mengimplementasikan teknologi Blockchain, sehingga sangat layak untuk diterapkan dalam bidang pendidikan, khususnya dalam pengelolaan artifak, dokumen digital maupun sertifikat dan portofolio sivitas akademika di JTK POLBAN. Sosio teknologi yang diacu dalam penerapan teknologi Blockchain dalam penelitian ini dikelompokan menjadi 6 fitur berikut:

1. Self-Sovereignty

2. Trust,

3. Transparency and Provenance,

4. Immutability,

5. Disintermediation, dan

6. Collaboration.

Berdasarkan hasil penelitian dan keberadaan aset serta wawancara dengan pihak terkait yang mengelola resource di lingkungan JTK POLBAN, maka saat ini teridentifikasi beberapa pengolahan dan pengelolaan asset yang dapat menerapkan teknologi Blockchain di JTK POLBAN. Empat cakupan yang dapat segera diimplementasikan adalah :

a. Pengelolaan Dokumen digital, baik berupa transkrip akademik, materi pengajaran maupun sertifikat pendamping ijazah adalah beberapa dokumen digital yang dapat dimodelkan dan diterbitkan dalam bentuk yang digital sehingga memudahkan pengaksesan dokumen secara global;

b. Penyimpanan dan pengelolaan portofolio sivitas akademika JTK POLBAN untuk keperluan peningkatan karier staf;

c. Pengelolaan Intellectual Property, dalam bentuk Paten dan HKI atas artifak dan produk perangkat lunak maupun ide yang dihasilkan baik oleh staf maupun mahasiswa JTK POLBAN;

d. Buku besar penelitian yang dilakukan JTK. Dengan diterapkannya teknologi Blockchain untuk buku besar penelitian di JTK akan memudahkan pengembangan keilmuan maupun evaluasi roadmap penelitian JTK dalam rentang waktu tertentu, dan dapat dijadikan profil JTK saat berkolaborasi dengan industri atau partner yang akan mengembangkan hasil penelitian di masa mendatang.

\section{Daftar Pustaka}

[1] Au, S. Don't forget what self sovereign identity system uPort doesn't claim to do (2017). Available at: https://decentralize.today/dont-forget-what-self-sovereign-identity-systemuport-doesn-t-claim-to-do1f43ca228575

[2] Christensen, Clayton M. (2003). The innovator's solution: creating and sustaining successful growth. Harvard Business Press. ISBN 978-1-57851-852-4.

[3] Dawes, Sharon S. Stewardship and usefulness: Policy principles for information-based transparency. Government Information Quarterly 27.4 (2010): 377-383

[4] Gupta, M., (2017). Blockchain for Dummies, IBM Limited Edition. Available at: https://www01.ibm.com/common/ssi/cgi-bin/ssialias?htmlfid=XIM12354USEN\&

[5] McKinsey (2016). How Blockchains could change the world. Available at: http://www.mckinsey.com/industries/high-tech/our-insights/how-Blockchains-couldchange-the-world

[6] Lewis, A. (2017). A gentle introduction to self-sovereign identity. Available at: https://bitsonblocks.net/2017/05/17/a-gentle-introduction-to-self-sovereign-identity 
[7] Piscini, E., Guastella, J., Rozman, A. and Nassim, T. (2016). Blockchain: Democratized trust. Distributed ledgers and the future of value. Deloitte University Press. Available at https://www2.deloitte.com/content/dam/Deloitte/uk/Documents/technology/deloitte-uktech-trends-2016Blockchain.pdf

[8] Winjum, J. O. (1971). Accounting and the rise of capitalism: an accountant's view. Journal of Accounting Research: 333-350.

\section{Biodata Penulis}

Ade Chandra Nugraha, adalah staf pengajar di Jurusan Teknik Komputer dan Informatika (JTK) Politeknik Negeri Bandung. Penulis adalah lulusan pendidikan diploma Politeknik ITB (tahun 1994) yang melanjutkan pendidikan sarjana dan meraih gelar Sarjana Sains (S.Si) dari Fakultas MIPA UNPAD pada tahun 1997. Tahun 2003 memperoleh gelar Magister Terapan (MT) dari Jurusan Informatika ITB. Penulis sangat termotivasi untuk mengeksplorasi beberapa teknologi informasi terkini. Hasil dari eksplorasi didominasi untuk peningkatan proses pembelajaran di lingkungan kampus maupun alternatif solusi terapan bagi industri. 